\title{
Mandatory ESG Reporting and XBRL Taxonomies Combination: ESG Ratings and Income Statement, a Sustainable Value-Added Disclosure
}

\author{
Alessio Faccia ${ }^{1,2, *(\mathbb{D}}$, Francesco Manni $^{3}$ and Fabian Capitanio ${ }^{4}$ \\ 1 School of Business and Law, Coventry University, Coventry CV1 5FB, UK \\ 2 Centre for Blockchain Technologies (CBT), University College London (UCL), London WC1E 6BT, UK \\ 3 Dipartimento di Economia Aziendale, Università Roma TRE, 00145 Rome, Italy; \\ francesco.manni@uniroma3.it \\ 4 Dipartimento di Medicina Veterinaria, Università di Napoli Federico II, 80137 Napoli, Italy; \\ fabian.capitanio@unina.it \\ * Correspondence: alessio.faccia@gmail.com
}

Citation: Faccia, A.; Manni, F.; Capitanio, F. Mandatory ESG Reporting and XBRL Taxonomies Combination: ESG Ratings and Income Statement, a Sustainable Value-Added Disclosure. Sustainability 2021, 13, 8876. https:/ / doi.org/10.3390/su13168876

Academic Editors: Collins Ntim, Dimu Ehalaiye, Ernest Gyapong, John Kalimilo Malagila and Jennifer Martínez-Ferrero

Received: 13 June 2021

Accepted: 5 August 2021

Published: 9 August 2021

Publisher's Note: MDPI stays neutral with regard to jurisdictional claims in published maps and institutional affiliations.

Copyright: (c) 2021 by the authors. Licensee MDPI, Basel, Switzerland. This article is an open access article distributed under the terms and conditions of the Creative Commons Attribution (CC BY) license (https:// creativecommons.org/licenses/by/ $4.0 /)$.

\begin{abstract}
Corporate financial statements address multiple stakeholders' needs. International Financial Reporting Standards (IFRSs), among others, allow two different classifications, "by function of expense" and "by nature of expense", for the statement of profit and loss and other comprehensive income for the period (from now on, also identified in short as "Income Statement", or "IS"). XBRL standards ensure compliance and consistency in financial statements' drafting and filing. XBRL taxonomies reflect the Income Statement IFRS disclosure requirement in the $\{310000\}$ and $\{320000\}$ codifications, respectively. Given the recent EU enhanced regulations that proposed extend mandatory ESG reporting to SMEs, this study aims to design and recommend an additional Income Statement to embed structured Environmental, Social, and Governance (ESG) disclosure. A restatement of the IS is organised following an adjusted Value-Added perspective to fit the purpose of sustainability disclosure. The above-mentioned Income Statement should be suitable and adaptable for entities of any size and operating in any industry. This goal can be achieved through customised input weighting. Therefore, this applied research can fill a current financial ESG disclosure gap, ensuring financial statements' comparability and encouraging additional mandatory disclosures through standardisation. Two more items in the XBRL (IFRS-based) structure are suggested, leading to the introduction of one fully structured statement " $\{330000\}-S t a t e m e n t$ of comprehensive income, profit or loss, by Added Value, ESG based" and a semi-structured " $\{814000\}-N o t e s-E S G$ Ratings and Reporting" to better discuss and disclose the assumptions and results of the ESG Statement.
\end{abstract}

Keywords: XBRL; ESG reporting; value-added; sustainable financial disclosure; IFRS; sustainability; income statement; statement of comprehensive income; EU Taxonomy Climate Delegated Act; NonFinancial Reporting Directive (NFRD)

\section{Introduction}

ESG disclosure is becoming increasingly regulated and essential to the stakeholders, more aware and sensitive to Environmental, Social, and Governance perspectives. Corporations play a significant role in the communities in which they operate [1-3]. Therefore, their accountability $[4,5]$ should be considered, measured, and systematically disclosed to ensure transparency, comparability, and stakeholders' awareness [6,7]. Attempts to measure and inform sustainability outcomes and financial performances have led to autonomous Sustainability Reports, discretionarily presented by the companies [8,9].

Structured financial statement disclosure, unlike ESG reporting, is enforced and highly regulated by laws, accounting standards, and other regulations [10-12]. EU law enforces large companies ("public-interest entities exceeding on their balance sheet dates the criterion 
of the average number of 500 employees during the financial year", Directive 2014/95/EU. This requirement integrates the previous Directive 2013/34/EU) "to disclose information on the way they operate and manage social and environmental challenges" [13], while all the other entities are likely to be soon expected to meet extended mandatory ESG reporting, according to the recent EU proposal [1,2].

The accounting process (see Figure 1) starts from (1) bookkeeping of companies' transactions, followed by (2) trial balance, (3) financial statement disclosure, and (4) financial statement analysis [14]. While sole traders and unincorporated entities are usually only expected to comply with the first two steps of the accounting process, incorporated companies must provide additional disclosure through structured, standardised financial statements that many stakeholders analyse through flows and ratios [15]. In this research, the authors will refer to incorporated entities only, as sole traders' and unincorporated entities' disclosure remain limited.

International Financial Reporting Standards (IFRSs) issued by the International Accounting Standard Board (IASB) apply to listed corporations of European countries and many others worldwide, resulting in the most popular accounting standards, followed by the US GAAPs (Generally Accepted Accounting Principles), along with many other accounting standards issued by national/local accounting professional bodies [16].

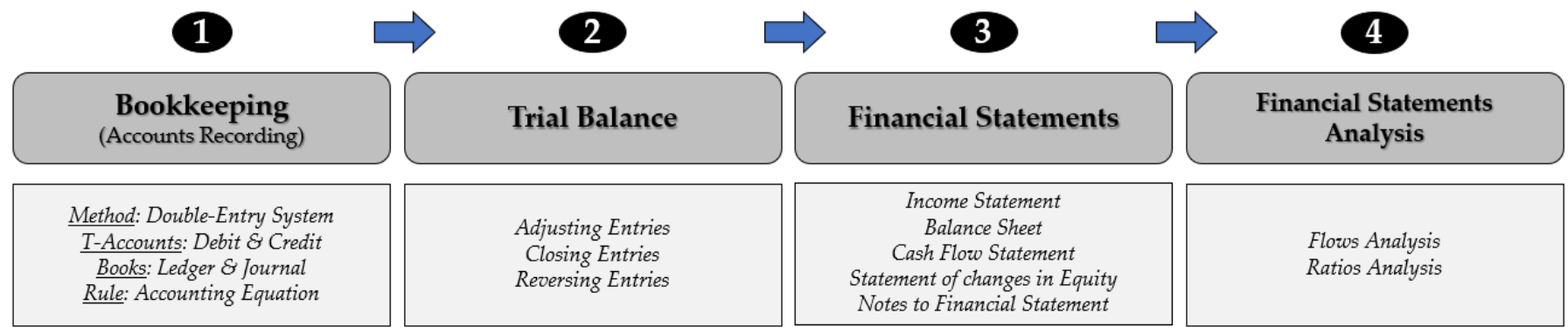

Figure 1. The accounting process.

The eXtensible Business Reporting Language (XBRL) is the "open international standard for digital business reporting" [17]. Incorporated entities in most countries should submit their annual report to public registers (i.e., Companies Houses in the UK, SEC's Edgar database in the US) codified according to this standardised language and file extension (XBRL) [18].

These standards aim to ensure accuracy (through formal mistakes avoidance and accounting equation balance), data processing automation, consistency, and comparability. Although the XBRL taxonomy was initially applied to the annual report schemes to better classify structured data, its application was progressively extended to the notes to include unstructured (text) data [19-21].

Corporate financial disclosure is essential to ensure transparency and accountability, and its filing according to the XBRL taxonomies is worldwide required. However, these standards still do not include any specific reference to the ESG disclosure. Therefore, this study traces the path to a further extension of the XBRL application to a standardised Sustainability Report. Although some attempts have been carried out to integrate financial and non-financial reporting [22] or to unify the XBRL reporting, using a "twin-track approach" [23], the configuration of a new XBRL Income Statement suitable for ESG purposes has never been considered so far.

In this research, Section 2 identifies materials and methods by defining research gaps and formulating three research questions. Framework and results are presented in Section 3, where the current ESG reporting methodologies are presented and compared with the proposed XBRL-based application. Discussions and conclusions are then included in Section 4 and followed by the limitations in Section 5. 


\section{Materials and Methods}

In this research, the authors started with the existing literature analysis on the following broad topics: ESG reporting, Sustainability Reports, XBRL applications, and financial statements regulations. Therefore, the investigation was extended to using the Value-Added Income Statement (VAIS) [24,25] and the existing ESG rating risk methodologies implemented by Sustainalytics [26] and MSCI [27] (which is also available in the Bloomberg database).

However, the literature review just served as the grounding framework to shift accounting practices by developing enhanced disclosures.

Indeed, this research approach led to the identification of the following research gaps and related research questions:

- XBRL taxonomies do not include ESG reports, but potentially only textual nonfinancial information.

- Value-Added Income Statements can better serve sustainability purposes.

\subsection{RQ1: Which Statement Can Better Represent the ESG Disclosure?}

Although (big) data analyses can currently rely on both structured, semi-structured, or unstructured data $[28,29]$, the accuracy, easiness, and readiness of quantitative (structured and semi-structured) data is far more preferrable than qualitative (unstructured data) [30-33], particularly when the standardisation is achieved through the XBRL taxonomy [34]. The potential exploitation of financial statement databases by the stakeholders can undoubtedly be more straightforward in case of numerical statements, rather than descriptive notes. Income Statement, Balance Sheet, and Cash Flow Statement are currently the main quantitative-structured statements that disclose entities' financial position. The Balance Sheet includes the resources and obligations of an entity at a particular time considered. The Income Statement records the value of the positive components of income (revenues) and negative ones (costs), illustrating their origin and composition. The Cash Flow Statement is aimed at ascertaining and illustrating the causes that explain the variation suffered by a certain financial resource in a given period of time, summarizing the incoming and outgoing movements that determined it in a scaled form. While the Balance Sheet is able to provide only "stock" values, referring to a given instant, and the Income Statement expresses flow values, referring to the economic dynamics, the Cash Flow Statement explains how the company has generated, employed, and collected liquidity. This is fundamental information for all the stakeholders that revolve around the company. The Income Statement, in particular, can be reclassified according to different perspectives.

\subsection{RQ2: How Can the VAIS Be Duly Re-Stated to Serve Sustainability Purposes?}

In the Sustainability Report, Added Value is understood as the difference between revenues and production costs that do not constitute remuneration for corporate stakeholders. From this point of view, the concept of Added Value adopted here differs from the more strictly accounting definition because it adopts the methodology proposed in 2001 by the Study Group for the Social Report (GBS, "Gruppo di Studio per il Bilancio Sociale" [35]) in Italy, which allows us to consider and measure how much wealth has been produced, how it was produced, and how it is distributed among the stakeholders. The determination of the Added Value highlights the ability to generate wealth, in the reference period, for the benefit of the various stakeholders, while respecting the cost-effectiveness of management and the expectations of the interlocutors themselves.

\subsection{RQ3: Is It Feasible to Develop an ESG-Based VAIS XBRL Template?}

Like most exploratory research, the creation of a development model falls within the very purpose of the article and is based on the positivist research model. Positivism is a philosophical movement that was widespread in nineteenth-century Europe, influencing philosophical thought and scientific, historical, and literary thought. It bases knowledge on facts and derives certainty exclusively from the observation of the experimental sciences. 
The use of the term "positive" reveals an ideology or a program of economic, social, or political action that sees science and technology as the foundation of its ideals and the tool to achieve them. All knowledge regarding matters is based on the "positive" data of experience; science is the only valid and practical knowledge. This research is qualitative, aimed at identifying a new disclosure model for companies' financial and non-financial information. Therefore, the search for qualitative information attempts to describe a topic rather than measure it. Qualitative research is less structured and aims to investigate the case to gather information about people's motivations, thinking, and attitudes. This framework provides a deep understanding of the research questions, making it more challenging to analyse the results. Therefore, a new theoretical framework is suggested to generate standardised ESG indicators/reports to disseminate better and consistently sustainability matters worldwide, supporting a transition to compulsory ESG extended disclosure for entities of any size (see Figure 2). Given that under the current regulations, apart from public interest entities (more than 500 employees), the ESG disclosure is merely voluntary, non-financial information can be eventually only included in the Notes to Financial Statements, under the anticipated mandatory standardised (enhanced disclosure), Sustainability, ESG Reports, and ESG Ratings will be included in the corpus of statements disclosure for any business. Convergence to the proposed, standardised model is suggested.

The article structure follows the logical sequence of analysis performed.
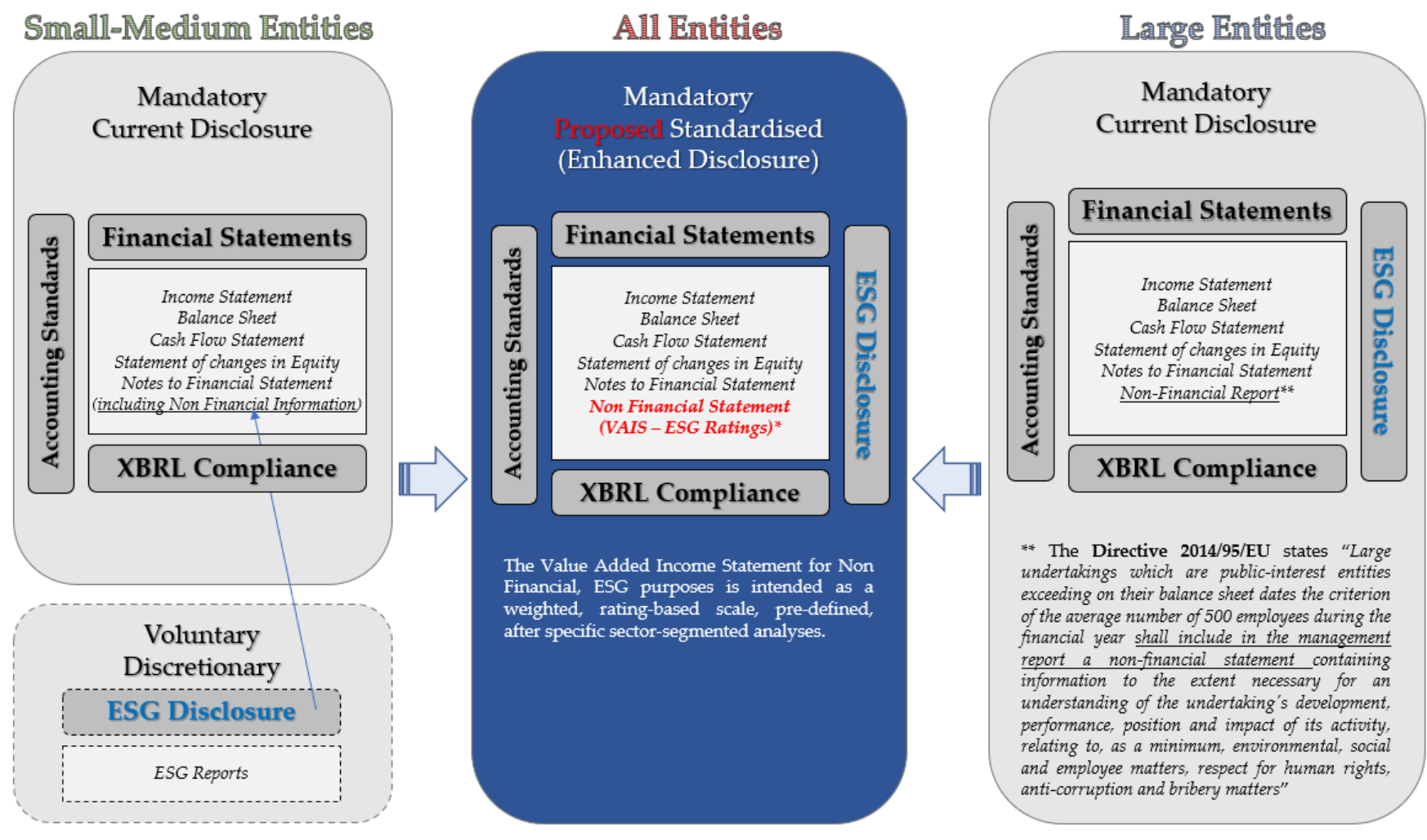

Figure 2. ESG disclosure framework.

Current and proposed frameworks are presented in the results section. Specific analysis of (a) accounting standards, regulations, and financial statements requirements, (b) Sustainability and ESG Reports, (c) ESG rating methodology, and (d) current XBRL taxonomy and enhanced XBRL taxonomy proposed. Limitations are also separately identified, and the model's feasibility, application, and benefits are presented in the Discussion and Conclusion section. Moreover, the proposed framework is supported by the recent EU provisional agreement on the European Climate Law [1,2]. Companies are already increasingly demonstrating their willingness to promote and build a corporate culture based on responsibility through activities based on social and environmental sustainability criteria, 
thus disclosing transparent reports to all stakeholders [36]. This trend is likely to continue as supported by these new regulations.

The main focus of this research is to design a suitable solution to combine mandatory ESG reporting with XBRL taxonomy. Implementation challenges associated with different entities' sizes are also identified and analysed. Therefore, the context of the regulation will be just introduced, providing the basic needed knowledge to the reader. At the same time, the authors focus more on the application, considered the most relevant contribution to the literature. This aim will be achieved by presenting a so-called "ESG Scoring ValueAdded Income Statement and Weighted Average ESG \% Score". This standardised disclosure follows existing approaches that proved very efficient in measuring and assessing business performances [36] and credit risk [37].

\section{Framework and Results}

Since the end of the 20th century, sustainable initiatives and reforms have followed increased awareness of corporate responsibility matters, other than economic and financial performances, including climate change, environmental, social, and governance [38].

Corporate stakeholders range from a variety of interests more or less aligned with the companies' ones. Different levels of strength characterise stakeholders' connections and influence with corporate actions. Multiple stakeholders gravitate around the company on orbits that vary according to the power of the interests they hold [39]. In the stakeholders' galaxy (see Figure 3), the most substantial interests are those held by the stakeholders linked to the company by related contractual or legal obligations.

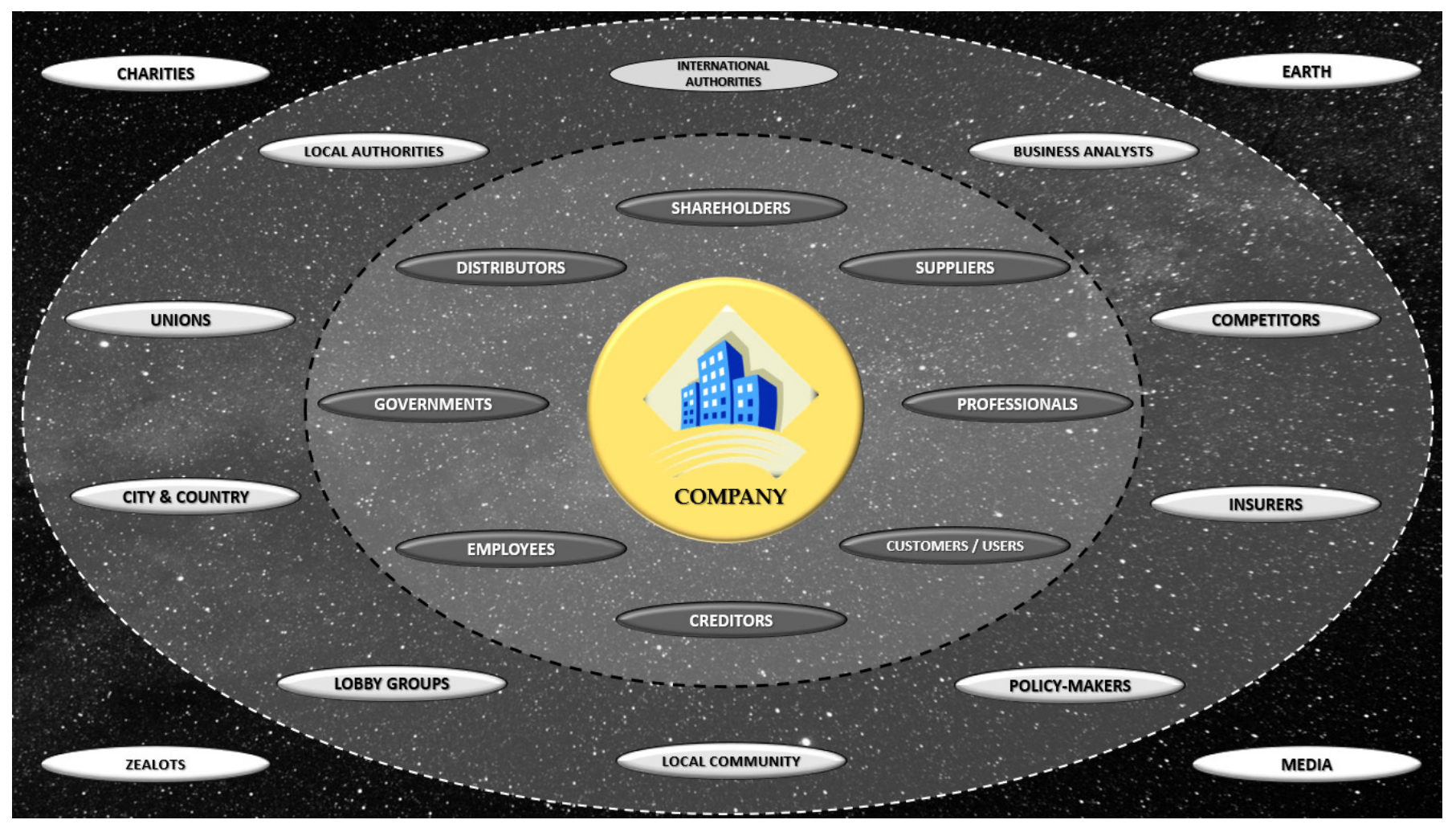

Figure 3. Company stakeholders' network galaxy.

Transactions with shareholders (dividend distribution, capital contribution), distributors (fees on sales), suppliers (purchases), governments (taxes), professionals such auditors and lawyers (professional fee), customers (sales), employees (wages and salaries), and creditors (interest expenses, borrowings) are always recorded in the bookkeeping process and reflected in the financial statements. Furthermore, many other entities indirectly hold stakes with the company. Among others, it is possible to consider business analysts, in- 
ternational authorities, local authorities, local community, unions, city and country, lobby groups, policy makers, insurers, competitors, media, earth, charities, and zealots.

The need for corporate accountability in terms of spillovers and other externalities directly or indirectly generated by company operations has been increasingly recognised and enforced through regulations, protocols, and agreements. However, the ESG and sustainability disclosure is still mostly voluntary and discretionary.

\subsection{Accounting Standards, Regulations, and Financial Disclosure}

The International Accounting Standards (IAS, issued up to 2001) or International Financial Reporting Standards (IFRS, starting from 2001) are accounting principles for the preparation of the financial statements issued by the IASB (International Accounting Standards Board) and approved by EU regulation. The introduction of international standards within the EU to prepare financial statements and consolidated financial statements took place in 2002. With the enforcement of the CE n. 1606/2002, the EU made it mandatory to adopt international principles in the consolidated financial statements of listed companies and banks and insurance companies starting from the 2005 financial statements. The purpose of the IAS/IFRS is to create a common accounting language for companies operating within the European community to make easier and more transparent the comparison between the financial statements and the financial information of companies operating in different countries to benefit investors. Their application has been increasingly extended worldwide, and it is already trendy in many other countries and geographic areas outside the EU [40].

Since 2006, the incorporated entities expected to use the IAS/IFRS international accounting standards for the preparation of the separate and consolidated financial statements are the following:

- Listed companies;

- Banks and financial intermediaries subject to supervision;

- All companies issuing widespread financial instruments;

- Unlisted insurance companies with reference only to the consolidated financial statements;

- Listed insurance companies.

The option, and not the obligation, to prepare the financial statements according to the IAS/IFRS standards is given to:

- Companies included in the consolidation of companies obliged to prepare consolidated financial statements in compliance with IAS;

- Companies subject to the obligation of preparation or included in a consolidated financial statement [41].

The criteria for evaluating and presenting company accounts to stakeholders according to IAS/IFRS standards ensure advantages that can be reflected on the company's image and reputation. These are exceptionally significant aspects if the company plans, in the medium term, to join the stock market, and therefore to be listed on the stock exchange. Reliability and analysis of the accounts and business processes lead to identifying numbers representing an Added Value and an advantage for the companies that decide to apply these international standards. Finally, it is also possible to obtain a return of image even with customers and suppliers.

The IAS/IFRS standards determine the use of specific accounting criteria set on the financial nature of the financial statement information. The substance over form principle is based on which transactions are accounted for regarding their legal nature and their substantial intrinsic nature. The fair value method is also envisaged to evaluate certain assets/liabilities instead of the cost criterion. The financial statements drafted according to international accounting standards aim for financial statements to be also examined possible stakeholders outside the company.

IAS/IFRS-compliant financial statements must include the following documents:

- The Statement of Financial Position (Balance Sheet); 
- $\quad$ The Statement of Comprehensive Income (Income Statement);

- Statement of Changes in Shareholders' Equity;

- The Cash Flow Statement, a document used to provide users of the financial statements with information on cash flows occurring during the year;

- The Notes with the function of adding and clarifying information can be obtained from the financial statements [42].

\subsection{Sustainability-ESG Reports}

EU regulations require large companies to disclose certain information on how they operate and manage social and environmental challenges. This disclosure obligation is intended to support investors, consumers, policy makers, and other interested parties in evaluating the non-financial performance of large companies by encouraging them to develop a responsible approach.

Directive 2014/95/EU, also known as the Non-Financial Reporting Directive (NFRD), sets the rules on disclosing non-financial information and on diversity by large companies. This Directive amends the Accounting Directive 2013/34/EU. Companies must include non-financial statements, in unstructured textual formats, in their annual reports starting in 2017.

The Non-Financial Reporting Directive applies only to significant public interest companies with over 500 employees, resulting in approximately 6000 large companies and groups across the European Union, including banks, insurance companies, and other designated companies by national authorities as an entity of public interest.

Under the Directive mentioned above, large companies must submit reports on the policies they implement concerning environmental protection, social responsibility and treatment of employees, respect for human rights, anti-corruption, and diversity on the boards of directors (in terms of age, gender, training, and professional background).

Directive 2014/95/EU gives companies considerable flexibility in disclosing relevant information in the way they find most useful. Companies can use international, European, or national guidelines to produce their statements. For example, they can base their statements on United Nations Global Compact, OECD guidelines for multinational companies, or ISO 26000.

In June 2017, the European Commission published its guidelines to help companies disclose environmental and social information. However, these guidelines are not mandatory, and companies may decide to use international, European, or national policies based on their characteristics or business environment. Finally, it should be noted that, in June 2019, the European Commission published guidelines on reporting climate-related information, which in practice consist of a new supplement to the existing guidelines on non-financial reporting, which remain applicable.

The European Commission initially determined the Action Plan on "Financing Sustainable Growth" back in March 2018. Furthermore, the recent EU Taxonomy Climate Delegated Act adopted by the European Commission on 21 June 2021 is part of a broader European Green Deal strategy, further recently enhanced on 4 June 2021 [43].

These acts not only are the most recent among many other international reforms that aim to tackle climate change (ranging from Kyoto Protocol (1997) to Paris Climate Change Agreement (2016)), but they are also the most relevant in terms of disclosure enforcement. Moreover, these regulations turn ESG reporting into mandatory disclosure while the European Commission implements suitable standards to reduce the green-washing risk.

However, all the above are based on unstructured data generated in textual formats (eventually also reported in the Notes of the Financial Statements) to ensure greater flexibility based on the specific characteristics of the industries in which the companies operate.

\subsection{Current ESG Rating Methodologies}

An already existing and successful application mitigates the need for unstructured flexible information through numerical indicators, as is the case of ESG Ratings. These 
ratings demonstrate that it is possible to achieve a comprehensive methodology that applies to all the companies, suitably adapted/adjusted for each industry. Examination of the existing literature, Sustainalytics, MSCI, and Bloomberg resulted in the most popular international providers of ESG Ratings. However, while Sustainalytics and MSCI disclosed their methodologies, the proprietary one developed by Bloomberg was not made public, and it is also limited to the oil and gas sector. Therefore, the authors' analyses only focused on the two available methodologies.

Indeed, measuring externalities (both positive and negative) is challenging. Many other market players usually influence the effect generated by the company action. Therefore, externalities cannot be easily (entirely) attributed to a specific entity, and determining the weight of contribution can be even more difficult. However, Sustainalytics and MSCI seem to have implemented and tested consistent alternative methodologies to overcome the challenges. Both companies tested their models and achieved statistically reliable rankings. Both methods use a combination of quantitative-structured and qualitative-unstructured data referring to the industry (and sub-industry) and the specific company (such as 10k, Sustainability Reports, proxy report, AGM results). The main limitation that can be identified is that the examined methodologies seem to focus mainly on governance and sustainability rather than environmental matters. This concern is not surprising, as little data can be placed in the disclosures and matched with specific risks.

The rating scale used by Sustainalytics is based on a generally mixed ESG outcome that ranges from Negligible, Low, Medium, High, to Severe. The rating scale used by MSCI ranges from AAA, AA, A, BBB, BB, B, to CCC. However, there is no specific indication of how each factor (Environmental, Social, and Governance) contributed to the attributed rating when tested in the respective websites' research engines.

However, given that the MSCI ESG Ratings are also available in Bloomberg Terminals (not to be confused with the proprietary ESG Ratings developed by Bloomberg itself) [44], it can be noticed that specific scores are attributed to the Environmental Social and Governance elements. Moreover, the average of these detailed results does not match the overall outcome, suggesting that variable weights are attributed to each component.

\subsection{XBRL Taxonomy and Value-Added Income Statement \\ 3.4.1. Current Taxonomy}

The most popular XBRL taxonomy is considered for this article purposes. Namely, the last updated, adopted to submit financial statements compliant with the IAS/IFRS accounting standards [45].

As already recently highlighted by a report published by the Spanish Central Bank [46], "The multiplicity of standards and recommendations and the fact that there is still no XBRL taxonomy for ESG reporting, which would make this data computer-readable, means that analysts have to go through usually lengthy pdf documents to extract the key information they require for their analysis, whether it is for supervisory, credit assessment, investment or other purposes". According to the authors, this situation usually results in ESG disclosure provided in a separate document, non-XBRL compliant.

However, although in textual unstructured format, it is still possible to argue that ESG disclosure could still be included in the XBRL taxonomy, namely in the general residual codification " $\{880000\}$ Notes-Additional information" (Appendix A, Table A1).

\subsubsection{Value-Added Income Statement}

In Sustainability Reports, Value-Added is considered as the difference between the revenues and costs of production. It can be therefore considered as the "difference between revenues and costs incurred for the purchase of production factors from other companies, and thus represents the value that the internal production factors of the company, risk capital and labour, have "added" to the inputs attained from outside" [47].

Added Value (or Value-Added) in sustainability studies assumes a different meaning than in the accounting field. Indeed, it can be referred to the methodology suggested 
in 2001 by the Study Group for the Social Report (GBS, "Gruppo di Studio per il Bilancio Sociale" [35]) in Italy. Mei [48-50] and Manni [51-54] further refined the methodology above. According to this perspective, the Added Value can bridge the Sustainability Report with the Financial Statements. Added Value production and distribution allow financial statements analyses from the stakeholders' points of view (see Figure 4).

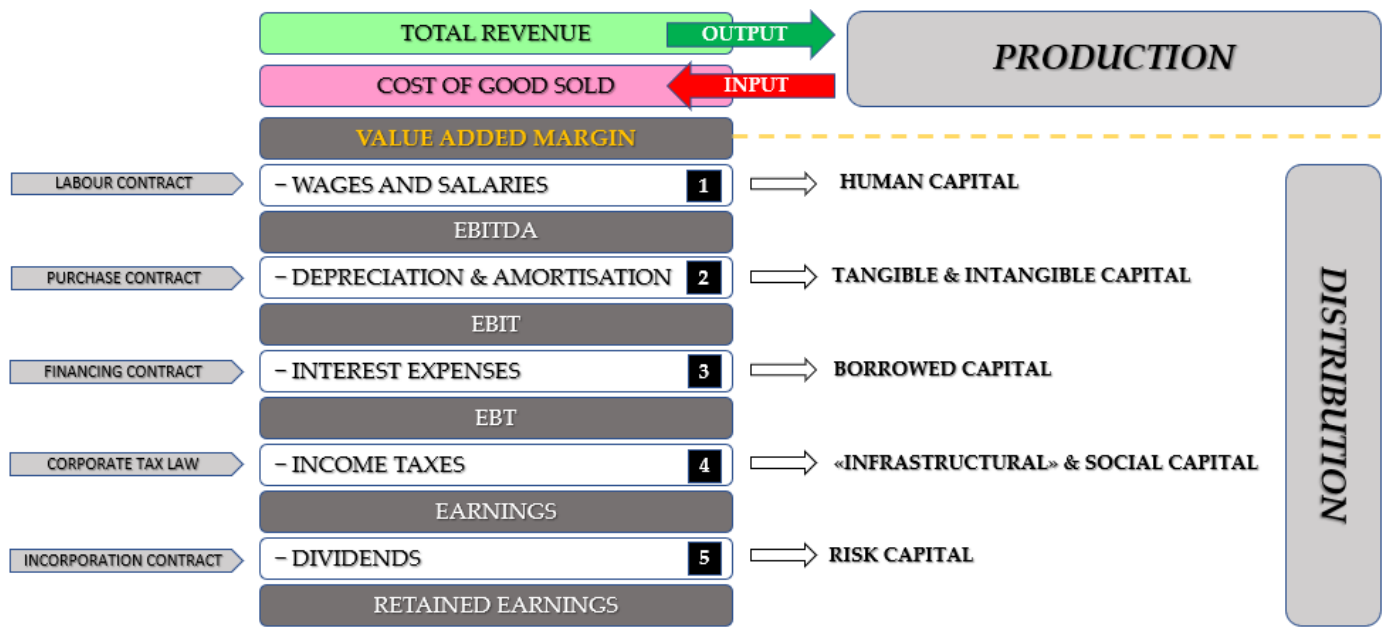

Figure 4. Value-Added Income Statement.

The Added Value generated by the production (intended as a difference between customer revenues and raw production factors) is distributed to different contributing capitals with peculiar priorities and proportions. Although the ranking is set by contracts (labour, purchase, financing) or by law (taxation), the proportions may vary, depending on the company's performance (see Figure 5).

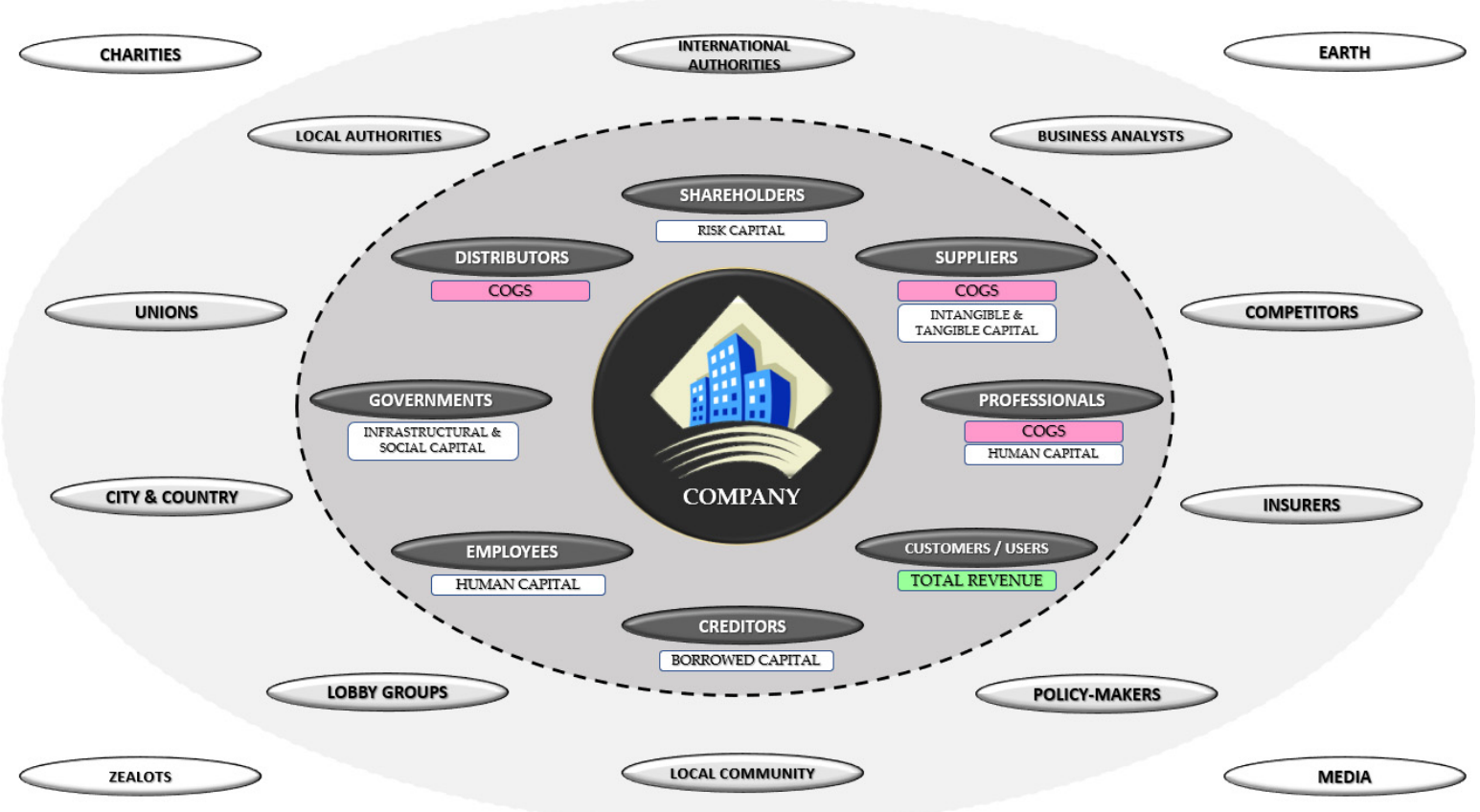

Figure 5. Company stakeholders' network galaxy and Value-Added Income Statement.

Addressing "RQ1—Which Statement can better represent the ESG disclosure?" and "RQ2: How can the VAIS be duly re-stated to serve sustainability purposes?" the above findings safely and consistently demonstrate that the VAIS seems to be the most appropriate 
statement to disclose ESG matters. The proposed extended Value-Added Income Statement rooted on the Italian GBS Model implemented back in 2001 further reinforce the validity of this approach by better mapping and matching stakeholders and returns.

\subsubsection{Enhanced Taxonomy}

Given the above-presented findings, supported by the existing literature [22,23,49-54], it is now possible to address "RQ3: Is it feasible to develop an ESG-based VAIS XBRL template?" by developing a new enhanced VAIS, considered the primary outcome of this research.

The first step was to add new codes to the existing taxonomy (Appendix A, Table A2), listed below.

$\{330000\}$ Statement of comprehensive income, profit or loss, by Added Value, ESG-based $\{814000\}$ Notes-ESG Ratings and Reporting below.

The essential XBRL coding that can be added to the existing taxonomy is presented

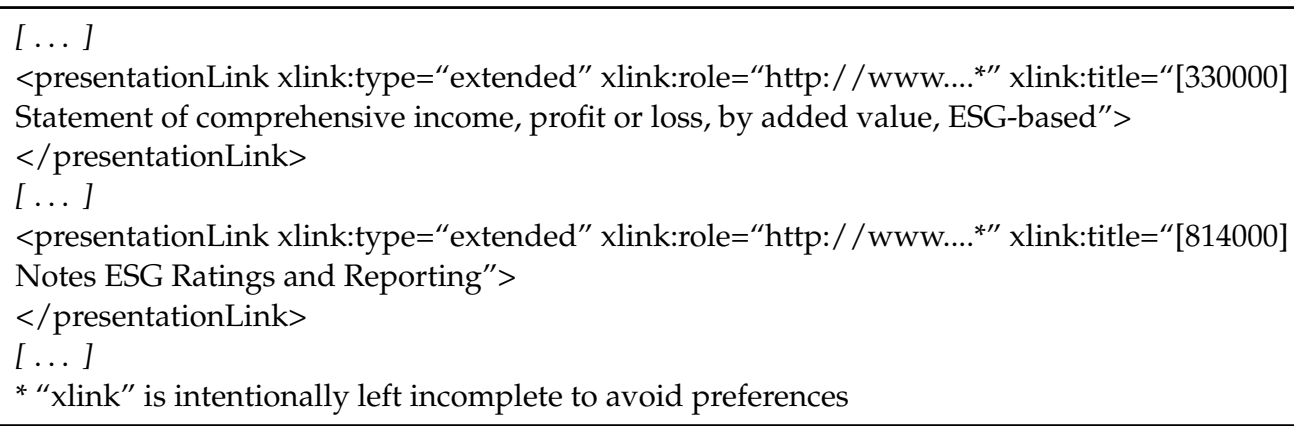

The second step in the model implementation identified the most suitable approach in applying the ESG scores to the VAIS. According to the most relevant literature [55] and following the already developed methods adopted by the rating agencies, a flexible Weighted Average ESG Score was selected.

Identifying subtotals (margins) in the Income Statement helped to match the ValueAdded distributions to the stakeholders. Therefore, detailed specific weighted ESG scores can be further assigned to each IS item leading to better disclosure.

Financial and non-financial stakeholders are expected to be considered in the final ESG outcome, consistently and thoughtfully disclosing ESG matters through a detailed combination (Weighted Average) of multiple scores based on semi-structured data analyses.

The list of all the stakeholders and sub-scores provided in Figure 6 can be considered a general design. All the Financial Stakeholders are usually essential. A zero weight can be eventually assigned if the related capital is missing (i.e., company fully financed by equity, in which no interest expenses are accrued). However, inclusion and exclusion of any non-financial stakeholders can be considered as they might depend on the influence and relevance to the specific company/industry.

A rating-based scale could be prepared after testing a suitable sample to assess risks and companies' responsibility in the medium-long term, to be further refined over time. 


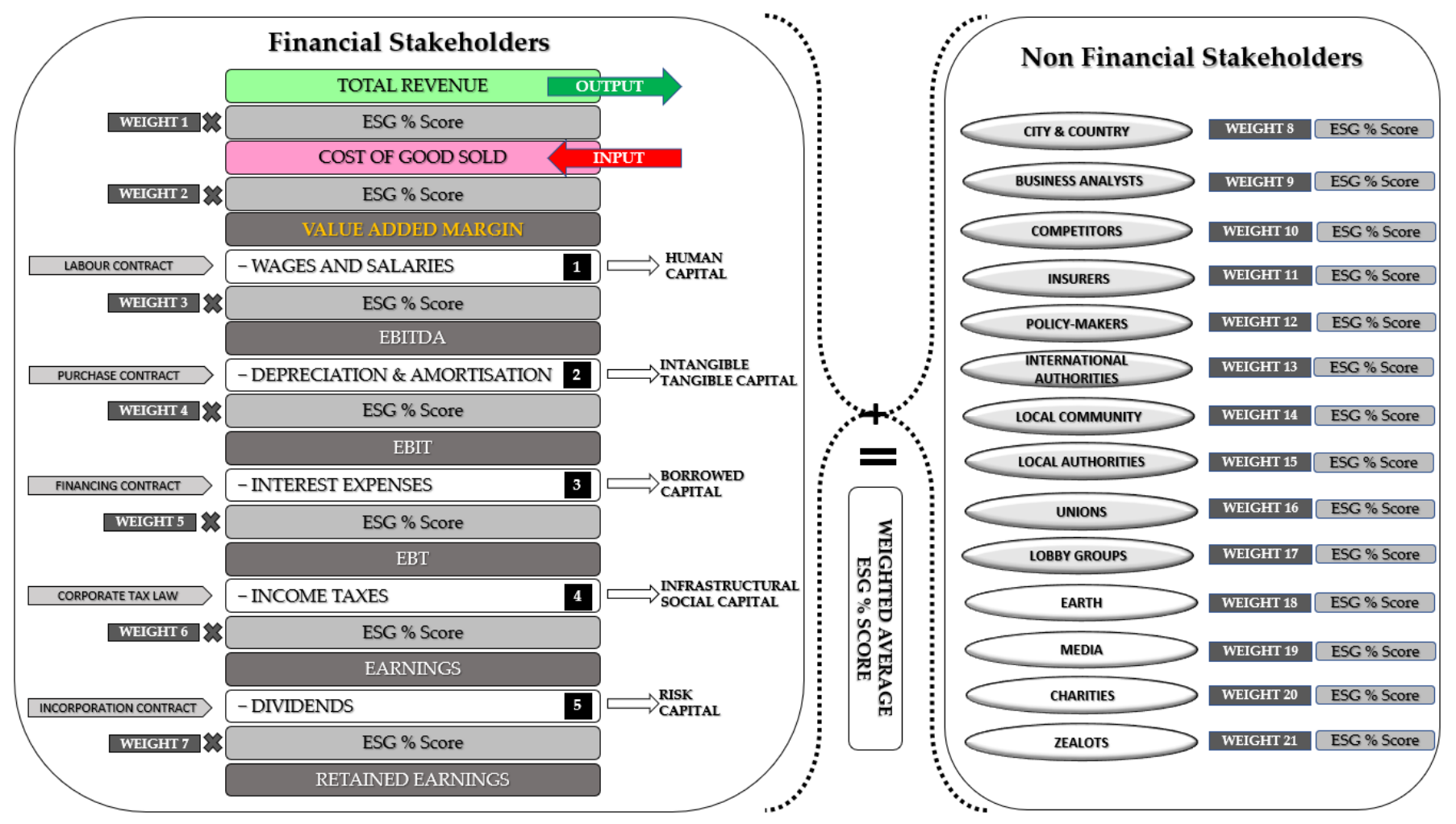

Figure 6. ESG Scoring Value-Added Income Statement and Weighted Average ESG \% Score.

\subsubsection{Overcoming Implementation Challenges}

This model does not come without specific challenges. Accountants, regulators, and stakeholders more in general must balance the trade-off between a transparent, complete disclosure and the cost of its achievement. Despite its benefits in terms of standardisation and error reductions, the XBRL taxonomy encountered practitioners' resistance since its very first introduction [56]. Indeed, it generates additional costs in terms of training, software development, and time-consuming filing processes $[57,58]$. The development of a weighted scoring system can undoubtedly be considered even far more complex.

According to the authors' perspective, however, the implementation of such a model can still be feasible, if the below steps are followed:

1. A specific expert panel should be appointed by the EU to identify the relevant stakeholders to be considered and the variables to be included in the model;

2. Massive and extended testing, using the big data (already available) should lead to refined ESG rating systems, customised after suitable sector segmentation;

3. Freeware, user-friendly (possibly automated) software should be provided to the entities to help minimising the implementation costs;

4. Continuous update and model refinement.

\section{Discussion and Conclusions}

Increased awareness in corporate social responsibility progressively leads to enhanced regulation extending the enforcement of non-financial disclosure previously only voluntarily prepared.

ESG reporting has been considered thus far as an additional non-financial source of information to be disclosed as a separate document outside the XBRL framework. Financial statements more often already include some pieces of ESG information. However, they can be only and eventually disclosed through unstructured or semi-structured textual forms in the residual code "\{880000\} Notes-Additional Information". 
The authors identified the need for a structured, regulated, and quantitative ESGbased statement in the form of a Value-Added Income Statement.

Income Statement re-stated in a Value-Added perspective has already been considered and successfully presented by relevant literature in the past to serve CSR purposes. The VAIS is further developed and matched with weighted ESG scores consistently assigned to financial and non-financial stakeholders according to their relevance in the proposed model.

Two additional items in the XBRL (IFRS-based) structure are suggested, leading to the introduction of one fully structured statement, " $\{330000\}$-Statement of comprehensive income, profit or loss, by Added Value, ESG based" and a semi-structured " $\{814000\}$ Notes-ESG Ratings and Reporting", to better discuss and disclose the assumptions and results of the ESG Statement.

According to the authors, given its complexity, the development, weighting choice, and preparation of ESG-based-VAIS should be delegated to independent external entities (such as Sustainalytics or MSCI), as in the case of the credit-risk rating agencies. These entities should be accredited by the EU commission, demonstrate independence, and ensure high-quality shared standards.

Although this is an expensive option that will charge an additional economic burden to the companies, it can be considered the best alternative to ensure transparency and avoid green-washing practices.

Combining mandatory ESG reporting and XBRL can be considered the natural and necessary subsequent step to ensure and enforce fair and comparable CSR disclosure. Therefore, this research addresses three complementary research questions and follows a modelling methodology to track the path for future shifts in the regulatory framework.

The model proposed in Figure 6 ensures compliance to different challenging needs as it is, at the same time:

- Flexible enough, in the weighting attribution;

- Structured to ensure comparability and consistency;

- $\quad$ XBRL-based to enforce its preparation according to an international standard;

- $\quad$ Scoring-oriented to provide a systematic uniform result.

Compared to the previous literature [22,23] that suggested combining existing integrated sustainability reporting, this research presents a feasible model to integrate and fit the ESG disclosure into a weighted, rating-oriented Income Statement. Empirical analyses using the proposed module will be separately demonstrated in future research (under development and almost completed).

\section{Limitations}

This research is limited to a general modelling design of a feasible and valuable application of the currently available technologies and practices. Model testing is expected to be performed soon. The successful implementation of the model mainly depends on the impact it will generate on the policy makers.

Author Contributions: Conceptualisation, A.F. and F.M.; methodology, A.F.; validation, F.M. and F.C.; formal analysis, A.F.; investigation, A.F.; resources, A.F., F.M. and F.C.; data curation, A.F.; writing-original draft preparation, A.F.; writing-review and editing, A.F.; visualisation, A.F.; supervision, F.M. and F.C.; project administration, A.F. All authors have read and agreed to the published version of the manuscript.

Funding: This research received no external funding.

Institutional Review Board Statement: Not applicable.

Informed Consent Statement: Not applicable.

Data Availability Statement: Not applicable.

Conflicts of Interest: The authors declare no conflict of interest. 


\section{Appendix A}

Table A1. Current IFRS, XBRL compliant taxonomy.

\begin{tabular}{|c|c|c|}
\hline Code & Description & Data Type \\
\hline$\{110000\}$ & General information about financial statements & Semi-structured \\
\hline$\{210000\}$ & Statement of financial position, current/non-current & structured \\
\hline$\{220000\}$ & Statement of financial position, order of liquidity & Structured \\
\hline$\{310000\}$ & Statement of comprehensive income, profit or loss, by function of expense & Structured \\
\hline$\{320000\}$ & Statement of comprehensive income, profit or loss, by nature of expense & Structured \\
\hline$\{410000\}$ & Statement of comprehensive income, OCI components presented net of tax & structured \\
\hline$\{420000\}$ & Statement of comprehensive income, OCI components presented before tax & Structured \\
\hline$\{510000\}$ & Statement of cash flows, direct method & Structured \\
\hline$\{520000\}$ & Statement of cash flows, indirect method & Structured \\
\hline$\{610000\}$ & Statement of changes in equity & Structured \\
\hline$\{710000\}$ & Statement of changes in net assets available for benefits & Structured \\
\hline$\{800100\}$ & Notes-Subclassifications of assets, liabilities and equities & Semi-structured \\
\hline$\{800200\}$ & Notes-Analysis of income and expense & Semi-structured \\
\hline$\{800300\}$ & Notes-Statement of cash flows, additional disclosures & Semi-structured \\
\hline$\{800400\}$ & Notes-Statement of changes in equity, additional disclosures & Semi-structured \\
\hline$\{800500\}$ & Notes-List of notes & Unstructured \\
\hline$\{800600\}$ & Notes-List of accounting policies & Unstructured \\
\hline$\{810000\}$ & Notes-Corporate information and statement of IFRS compliance & Unstructured \\
\hline$\{811000\}$ & Notes-Accounting policies, changes in accounting estimates and errors & Unstructured \\
\hline$\{813000\}$ & Notes-Interim financial reporting & Unstructured \\
\hline$\{815000\}$ & Notes-Events after reporting period & Unstructured \\
\hline$\{816000\}$ & Notes-Hyperinflationary reporting & Unstructured \\
\hline$\{817000\}$ & Notes-Business combinations & Unstructured \\
\hline$\{818000\}$ & Notes-Related party & Unstructured \\
\hline$\{819100\}$ & Notes-First time adoption & Unstructured \\
\hline$\{822100\}$ & Notes-Property, plant and equipment & Semi-structured \\
\hline$\{822200\}$ & Notes-Exploration for and evaluation of mineral resources & Semi-structured \\
\hline$\{822390\}$ & Notes-Financial instruments & Semi-structured \\
\hline$\{823000\}$ & Notes-Fair value measurement & Semi-structured \\
\hline$\{823180\}$ & Notes-Intangible assets & Semi-structured \\
\hline$\{824180\}$ & Notes-Agriculture & Unstructured \\
\hline$\{824500\}$ & Regulatory deferral accounts & Semi-structured \\
\hline$\{825100\}$ & Notes-Investment property & Semi-structured \\
\hline$\{825480\}$ & Notes-Separate financial statements & Semi-structured \\
\hline$\{825700\}$ & Notes-Interests in other entities & Semi-structured \\
\hline$\{825900\}$ & Notes-Non-current asset held for sale and discontinued operations & Semi-structured \\
\hline$\{826380\}$ & Notes-Inventories & Semi-structured \\
\hline$\{827570\}$ & Notes-Other provisions, contingent liabilities and contingent assets & Semi-structured \\
\hline$\{831150\}$ & Notes-Revenue from contracts with customers & Semi-structured \\
\hline$\{831400\}$ & Notes-Government grants & Semi-structured \\
\hline$\{832410\}$ & Notes-Impairment of assets & Semi-structured \\
\hline$\{832610\}$ & Notes-Leases & Semi-structured \\
\hline$\{832900\}$ & Notes-Service concession arrangements & Semi-structured \\
\hline$\{834120\}$ & Notes-Share-based payment arrangements & Semi-structured \\
\hline$\{834480\}$ & Notes-Employee benefits & Semi-structured \\
\hline$\{835110\}$ & Notes-Income taxes & Semi-structured \\
\hline$\{836200\}$ & Notes-Borrowing costs & Semi-structured \\
\hline$\{836500\}$ & Notes-Insurance contracts & Semi-structured \\
\hline$\{836600\}$ & Notes-Insurance contracts (IFRS 17) & Semi-structured \\
\hline$\{838000\}$ & Notes-Earnings per share & Semi-structured \\
\hline$\{842000\}$ & Notes-Effects of changes in foreign exchange rates & Semi-structured \\
\hline$\{851100\}$ & Notes-Cash Flow Statement & Semi-structured \\
\hline$\{861000\}$ & Notes-Analysis of other comprehensive income by item & Semi-structured \\
\hline$\{861200\}$ & Notes-Share capital, reserves and other equity interest & Semi-structured \\
\hline$\{868200\}$ & $\begin{array}{l}\text { Notes-Rights to interests arising from decommissioning, restoration and } \\
\text { environmental rehabilitation funds }\end{array}$ & Semi-structured \\
\hline
\end{tabular}


Table A1. Cont.

\begin{tabular}{|c|c|c|}
\hline Code & Description & Data Type \\
\hline$\{868500\}$ & Notes-Members' shares in co-operative entities and similar instruments & Semi-structured \\
\hline$\{871100\}$ & Notes-Operating segments & Semi-structured \\
\hline$\{880000\}$ & Notes-Additional information & Semi-structured \\
\hline$\{901000\}$ & Axis-Retrospective application and retrospective restatement & Semi-structured \\
\hline$\{901100\}$ & Axis-Departure from requirement of IFRS & Semi-structured \\
\hline$\{901500\}$ & Axis-Creation date & Semi-structured \\
\hline$\{903000\}$ & Axis-Continuing and discontinued operations & Semi-structured \\
\hline$\{904000\}$ & Axis-Assets and liabilities classified as held for sale & Semi-structured \\
\hline$\{913000\}$ & Axis-Consolidated and separate financial statements & Semi-structured \\
\hline$\{914000\}$ & Axis-Currency in which information is displayed & Semi-structured \\
\hline$\{915000\}$ & Axis - Cumulative effect at date of initial application & Semi-structured \\
\hline$\{990000\}$ & Axis-Defaults & Semi-structured \\
\hline
\end{tabular}

Table A2. Proposed IFRS, XBRL compliant taxonomy that includes ESG reporting.

\begin{tabular}{|c|c|c|}
\hline Code & Description & Data Type \\
\hline$\{110000\}$ & General information about financial statements & Semi-structured \\
\hline$\{210000\}$ & Statement of financial position, current/non-current & Structured \\
\hline$\{220000\}$ & Statement of financial position, order of liquidity & Structured \\
\hline$\{310000\}$ & Statement of comprehensive income, profit or loss, by function of expense & Structured \\
\hline$\{320000\}$ & Statement of comprehensive income, profit or loss, by nature of expense & Structured \\
\hline$\{330000\}$ & Statement of comprehensive income, profit or loss, by Added Value, ESG-based & Structured \\
\hline$\{410000\}$ & Statement of comprehensive income, OCI components presented net of tax & structured \\
\hline$\{420000\}$ & Statement of comprehensive income, OCI components presented before tax & Structured \\
\hline$\{510000\}$ & Statement of cash flows, direct method & Structured \\
\hline$\{520000\}$ & Statement of cash flows, indirect method & Structured \\
\hline$\{610000\}$ & Statement of changes in equity & Structured \\
\hline$\{710000\}$ & Statement of changes in net assets available for benefits & Structured \\
\hline$\{800100\}$ & Notes-Subclassifications of assets, liabilities and equities & Semi-structured \\
\hline$\{800200\}$ & Notes-Analysis of income and expense & Semi-structured \\
\hline$\{800300\}$ & Notes-Statement of cash flows, additional disclosures & Semi-structured \\
\hline$\{800400\}$ & Notes-Statement of changes in equity, additional disclosures & Semi-structured \\
\hline$\{800500\}$ & Notes-List of notes & Unstructured \\
\hline$\{800600\}$ & Notes-List of accounting policies & Unstructured \\
\hline$\{810000\}$ & Notes-Corporate information and Statement of IFRS compliance & Unstructured \\
\hline$\{811000\}$ & Notes-Accounting policies, changes in accounting estimates and errors & Unstructured \\
\hline$\{813000\}$ & Notes-Interim financial reporting & Unstructured \\
\hline$\{814000\}$ & Notes_ESG Ratings and Reporting & Semi-structured \\
\hline$\{815000\}$ & Notes-Events after reporting period & Unstructured \\
\hline$\{816000\}$ & Notes-Hyperinflationary reporting & Unstructured \\
\hline$\{817000\}$ & Notes-Business combinations & Unstructured \\
\hline$\{818000\}$ & Notes-Related party & Unstructured \\
\hline$\{819100\}$ & Notes-First time adoption & Unstructured \\
\hline$\{822100\}$ & Notes-Property, plant and equipment & Semi-structured \\
\hline$\{822200\}$ & Notes-Exploration for and evaluation of mineral resources & Semi-structured \\
\hline$\{822390\}$ & Notes-Financial instruments & Semi-structured \\
\hline$\{823000\}$ & Notes-Fair value measurement & Semi-structured \\
\hline$\{823180\}$ & Notes-Intangible assets & Semi-structured \\
\hline$\{824180\}$ & Notes-Agriculture & Unstructured \\
\hline$\{824500\}$ & Regulatory deferral accounts & Semi-structured \\
\hline$\{825100\}$ & Notes-Investment property & Semi-structured \\
\hline$\{825480\}$ & Notes-Separate financial statements & Semi-structured \\
\hline$\{825700\}$ & Notes-Interests in other entities & Semi-structured \\
\hline$\{825900\}$ & Notes-Non-current asset held for sale and discontinued operations & Semi-structured \\
\hline$\{826380\}$ & Notes-Inventories & Semi-structured \\
\hline$\{827570\}$ & Notes-Other provisions, contingent liabilities and contingent assets & Semi-structured \\
\hline$\{831150\}$ & Notes-Revenue from contracts with customers & Semi-structured \\
\hline
\end{tabular}


Table A2. Cont.

\begin{tabular}{|c|c|c|}
\hline Code & Description & Data Type \\
\hline$\{831400\}$ & Notes-Government grants & Semi-structured \\
\hline$\{832410\}$ & Notes-Impairment of assets & Semi-structured \\
\hline$\{832610\}$ & Notes-Leases & Semi-structured \\
\hline$\{832900\}$ & Notes-Service concession arrangements & Semi-structured \\
\hline$\{834120\}$ & Notes-Share-based payment arrangements & Semi-structured \\
\hline$\{834480\}$ & Notes-Employee benefits & Semi-structured \\
\hline$\{835110\}$ & Notes-Income taxes & Semi-structured \\
\hline$\{836200\}$ & Notes-Borrowing costs & Semi-structured \\
\hline$\{836500\}$ & Notes-Insurance contracts & Semi-structured \\
\hline$\{836600\}$ & Notes-Insurance contracts (IFRS 17) & Semi-structured \\
\hline$\{838000\}$ & Notes-Earnings per share & Semi-structured \\
\hline$\{842000\}$ & Notes-Effects of changes in foreign exchange rates & Semi-structured \\
\hline$\{851100\}$ & Notes-Cash Flow Statement & Semi-structured \\
\hline$\{861000\}$ & Notes-Analysis of other comprehensive income by item & Semi-structured \\
\hline$\{861200\}$ & Notes-Share capital, reserves and other equity interest & Semi-structured \\
\hline$\{868200\}$ & $\begin{array}{l}\text { Notes-Rights to interests arising from decommissioning, restoration and } \\
\text { environmental rehabilitation funds }\end{array}$ & Semi-structured \\
\hline$\{868500\}$ & Notes-Members' shares in co-operative entities and similar instruments & Semi-structured \\
\hline$\{871100\}$ & Notes-Operating segments & Semi-structured \\
\hline$\{880000\}$ & Notes-Additional information & Semi-structured \\
\hline$\{901000\}$ & Axis-Retrospective application and retrospective restatement & Semi-structured \\
\hline$\{901100\}$ & Axis-Departure from requirement of IFRS & Semi-structured \\
\hline$\{901500\}$ & Axis-Creation date & Semi-structured \\
\hline$\{903000\}$ & Axis-Continuing and discontinued operations & Semi-structured \\
\hline$\{904000\}$ & Axis-Assets and liabilities classified as held for sale & Semi-structured \\
\hline$\{913000\}$ & Axis-Consolidated and separate financial statements & Semi-structured \\
\hline$\{914000\}$ & Axis-Currency in which information is displayed & Semi-structured \\
\hline$\{915000\}$ & Axis-Cumulative effect at date of initial application & Semi-structured \\
\hline$\{990000\}$ & Axis-Defaults & Semi-structured \\
\hline
\end{tabular}

\section{References}

1. EU-Press Release. Commission Welcomes Provisional Agreement on the European Climate Law. Available online: https: / / ec.europa.eu/commission/presscorner/detail/en/ip_21_1828 (accessed on 21 April 2021).

2. EU Extends Mandatory Sustainability Reporting to 50,000 Companies. Available online: https://www.esgtoday.com/eu-extendsmandatory-sustainability-reporting-to-50000-companies/ (accessed on 6 August 2021).

3. Hoang, T. The role of the integrated reporting in raising awareness of environmental, social and corporate governance (ESG) performance. In Stakeholders, Governance and Responsibility. Emerald Publishing Limited; Emerald Publishing Limited: Bingley, UK, 2018.

4. Escrig-Olmedo, E.; Muñoz-Torres, M.J.; Fernandez-Izquierdo, M.A. Socially responsible investing: Sustainability indices, ESG rating and information provider agencies. Int. J. Sustain. Econ. 2010, 2, 442-461. [CrossRef]

5. Du Rietz, S. Information vs knowledge: Corporate accountability in environmental, social, and governance issues. Account. Audit. Account. J. 2018, 31, 586-607. [CrossRef]

6. Băndoi, A.; Bocean, C.G.; Del Baldo, M.; Mandache, L.; Mănescu, L.G.; Sitnikov, C.S. Including sustainable reporting practices in corporate management reports: Assessing the impact of transparency on economic performance. Sustainability 2021, 13, 940. [CrossRef]

7. Dye, J.; McKinnon, M.; Van der Byl, C. Green gaps: Firm ESG disclosure and financial institutions' reporting Requirements. J. Sustain. Res. 2021, 3. [CrossRef]

8. Landrum, N.E.; Ohsowski, B. Identifying worldviews on corporate sustainability: A content analysis of corporate sustainability reports. Bus. Strategy Environ. 2018, 27, 128-151. [CrossRef]

9. Rosati, F.; Faria, L.G. Addressing the SDGs in sustainability reports: The relationship with institutional factors. J. Clean. Prod. 2019, 215, 1312-1326. [CrossRef]

10. Diouf, D.; Boiral, O. The quality of sustainability reports and impression management. Account. Audit. Account. J. 2017, 30, 643-667. [CrossRef]

11. Hoitash, R.; Hoitash, U.; Morris, L. eXtensible Business reporting language: A review and directions for future research. XBRL Res. 2020, 1, 1-56.

12. Beretta, V.; Demartini, M.C.; Lico, L.; Trucco, S. A tone analysis of the non-financial disclosure in the automotive industry. Sustainability 2021, 13, 2132. [CrossRef] 
13. Corporate Sustainability Reporting. Available online: https://ec.europa.eu/info/business-economy-euro/company-reportingand-auditing/company-reporting/corporate-sustainability-reporting_en (accessed on 6 August 2021).

14. Faccia, A.; Manni, F. Financial Accounting: Text and Cases; Aracne Editrice: Rome, Italy, 2019.

15. Mohana, R.P. Financial Statement Analysis and Reporting; PHI Learning Pvt. Ltd.: New Delhi, India, 2011.

16. DeGennaro, M. An economic comparison of US GAAP and IFRS. J. Int. Bus. Law 2017, 16, 7.

17. An Introduction to XBRL. Available online: https://www.xbrl.org/the-standard/what/an-introduction-to-xbrl/ (accessed on 11 June 2020).

18. Apostolou, A.K.; Nanopoulos, K.A. Interactive financial reporting using XBRL: An overview of the global markets and Europe. Int. J. Discl. Gov. 2009, 6, 262-272. [CrossRef]

19. Weglarz, G. Two worlds of data unstructured and structured. Inf. Manag. 2004, 14, 19.

20. O'Riain, S.; Curry, E.; Harth, A. XBRL and open data for global financial ecosystems: A linked data approach. Int. J. Account. Inf. Syst. 2012, 13, 141-162. [CrossRef]

21. Tsui, E.; Wang, W.M.; Cai, L.; Cheung, C.F.; Lee, W.B. Knowledge-based extraction of intellectual capital-related information from unstructured data. Expert Syst. Appl. 2014, 41, 1315-1325. [CrossRef]

22. Efimova, O.; Rozhnova, O.; Gorodetskaya, O. Xbrl as a tool for integrating financial and non-financial reporting. In The 2018 International Conference on Digital Science; Springer: Cham, Switzerland, 2019; pp. 135-147.

23. Seele, P. Digitally unified reporting: How XBRL-based real-time transparency helps in combining integrated sustainability reporting and performance control. J. Clean. Prod. 2016, 136, 65-77. [CrossRef]

24. McLeay, S. Value added: A comparative study. Account. Organ. Soc. 1983, 8, 31-56. [CrossRef]

25. Sabol, A.; Sverer, F. A review of the economic value added literature and application. UTMS J. Econ. $2017,8,19-27$.

26. Sustainalytics' ESG Risk Ratings Offer Clear Insights into the ESG Risks of Companies. Available online: https://www. sustainalytics.com/esg-ratings / (accessed on 11 June 2020).

27. What Is an MSCI ESG Rating? Available online: https:/ /www.msci.com/our-solutions/esg-investing/esg-ratings (accessed on 11 June 2020).

28. Cao, M.; Chychyla, R.; Stewart, T. Big data analytics in financial statement audits. Account. Horiz. 2015, 29, 423-429. [CrossRef]

29. Stewart, T.R. Data analytics for financial statement audits. Audit. Anal. 2015, 105-128. Available online: https://www. aicpa.org/content/dam/aicpa/interestareas/frc/assuranceadvisoryservices/downloadabledocuments/auditanalyticslookingtowardfuture.pdf\#page=130 (accessed on 6 August 2021).

30. Patibandla, R.L.; Veeranjaneyulu, N. Survey on clustering algorithms for unstructured data. In Intelligent Engineering Informatics; Springer: Singapore, 2018; pp. 421-429.

31. Das, T.K.; Kumar, P.M. Big data analytics: A framework for unstructured data analysis. Int. J. Eng. Sci. Technol. $2013,5,153$.

32. Syed, A.; Gillela, K.; Venugopal, C. The future revolution on big data. Future 2013, 2, 2446-2451.

33. Gandomi, A.; Haider, M. Beyond the hype: Big data concepts, methods, and analytics. Int. J. Inf. Manag. 2015, 35, 137-144. [CrossRef]

34. Vasarhelyi, M.A.; Chan, D.Y.; Krahel, J.P. Consequences of XBRL standardization on financial statement data. J. Inf. Syst. 2012, 26, 155-167. [CrossRef]

35. Gruppo Bilancio Sociale. 2020. Available online: http:/ /www.gruppobilanciosociale.org/ (accessed on 5 November 2020).

36. Altman, E.I. A fifty-year retrospective on credit risk models, the Altman Z-score family of models and their applications to financial markets and managerial strategies. J. Credit. Risk 2018, 14, 34. [CrossRef]

37. Le Leslé, V.; Avramova, M.S. Revisiting Risk-Weighted Assets; International Monetary Fund: Washington, DC, USA, 2012.

38. Brooks, C.; Oikonomou, I. The effects of environmental, social and governance disclosures and performance on firm Value: A review of the literature in accounting and finance. Br. Account. Rev. 2018, 50, 1-15. [CrossRef]

39. Kamal, Y. Stakeholders expectations for CSR-related corporate governance disclosure: Evidence from a developing country. Asian Rev. Account. 2021, 29, 97-127. [CrossRef]

40. Song, X.; Trimble, M. The Historical and current status of global ifrs adoption: Obstacles and opportunities for researchers. Int. J. Account. 2020, 2250001. [CrossRef]

41. EU Regulation, n. 1606/2002. Available online: https:/ / eur-lex.europa.eu/legal-content/en/ALL/?uri=CELEX\%3A32002R1606 (accessed on 6 August 2021).

42. Barker, R.; Teixeira, A. Gaps in the IFRS conceptual framework. Account. Eur. 2018, 15, 153-166. [CrossRef]

43. Commission Delegated Regulation (EU). 04.06.2021. Supplementing Regulation (EU) 2020/852 of the European Parliament and of the Council by Establishing the Technical Screening Criteria for Determining the Conditions under Which an Economic Activity Qualifies as Contributing Substantially to Climate Change Mitigation or Climate Change Adaptation and for Determining Whether That Economic Ac-tivity Causes no Significant Harm to Any of the Other Environmental Objectives. Available online: https: / / op.europa.eu/en/publication-detail/-/publication/ec9fae45-2b5e-11eb-87b7-01aa75ed71a1/language-en\#: \{\}: text=\%E2\%80\%A6\%2F...-, supplementing\%20Regulation\%20(EU)\%202020\%2F852\%20of\%20the\%20European\%20Parliament, change $\% 20$ adaptation $\% 20$ and $\% 20$ for\%20determining (accessed on 6 August 2021).

44. Bloomberg to Offer MSCI ESG Research Data on the Bloomberg Terminal. Available online: https://www.bloomberg.com/ company/press/bloomberg-to-offer-msci-esg-research-data-on-the-bloomberg-terminal/ (accessed on 11 June 2020).

45. IASB. IFRS Taxonomy Illustrated a View of the IFRS Taxonomy 2021 (Organised by Financial Statement); IASB: London, UK, 2021. 
46. Moreno, Á.I.; Caminero, T. Application of text mining to the analysis of climate-related disclosures. Banco Esp. 2020. [CrossRef]

47. Faccia, A.; Mataruna-Dos-Santos, L.J.; Munoz Helù, H.; Range, D. Measuring and monitoring sustainability in listed european football clubs: A value-added reporting perspective. Sustainability 2020, 12, 9853. [CrossRef]

48. Gruppo Bilancio Sociale. 2020. Available online: http://www.gruppobilanciosociale.org/pubblicazioni (accessed on 11 June 2020).

49. Mei, O.G. Metodologie Quantitative di Determinazione del Valore Aggiunto Aziendale; Libreria Goliardica: Trieste, Italy, 1986.

50. Gabrovec Mei, O.; Vitezi, N. Social and environmental responsibility-accountability and reporting in the EU. In Proceedings of the IIA International Conference Economic System of the European Union and Adjustment of the Republic of Croatia, Lovran, Croatia, 8 April 1999.

51. Manni, F. Il bilancio sociale nello sport professionistico. Econ. Aziend. Online 2012, 12, 59-68.

52. Manni, F. Riflessioni sul bilancio sociale nel contesto non profit. Econ. Aziend. Online 2010, 1, $59-65$.

53. Manni, F. Responsabilità Sociale e Informazione Esterna D'impresa: Problemi, Esperienze e Prospettive del Bilancio Sociale; G. Giappichelli: Turin, Italy, 1998.

54. Manni, F.; Faccia, A. The business going concern: Financial return and social expectations. In Sustainable Development and Social Responsibility; Springer: Berlin/Heidelberg, Germany, 2020; Volume 1, pp. 201-213.

55. Altman, E.I. The Use of Credit Scoring Models and the Importance of a Credit Culture; Stern School of Business, New York University: New York, NY, USA, 2002.

56. Krisko, A. The role of resistance in incorporating XBRL into financial reporting practices. Int. J. Account. Econ. Stud. 2017, 5, 100-111. [CrossRef]

57. Pinsker, R.; Li, S. Costs and benefits of XBRL adoption: Early evidence. Commun. ACM 2008, 51, 47-50. [CrossRef]

58. Hannon, N.J. Does XBRL cost too much? Strateg. Financ. 2006, 1, 59-61. 